\title{
2 I 38 Early atherosclerosis in the carotid and coronary territories: a cardiovascular magnetic resonance and multidetector computed tomography analysis
}

\author{
Timothy H Greenwell*1, Michael C Leung1, Gary YH Liew ${ }^{1}$, Karen SL Teo1, \\ Derek P Chew ${ }^{2}$, Angelo Carbone ${ }^{1}$, Adam J Nelson ${ }^{1}$, Matthew I Worthley ${ }^{1}$ and \\ Stephen G Worthley ${ }^{1}$
}

Address: ${ }^{1}$ University of Adelaide, Adelaide, Australia and ${ }^{2}$ Flinders University, Adelaide, Australia

* Corresponding author

from I th Annual SCMR Scientific Sessions

Los Angeles, CA, USA. I-3 February 2008

Published: 22 October 2008

Journal of Cardiovascular Magnetic Resonance 2008, I0(Suppl I):A407 doi:10.I I86/I532-429X-I0-SI-A407

This abstract is available from: http://jcmr-online.com/content/I0/SI/A407

(c) 2008 Greenwell et al; licensee BioMed Central Ltd.

\section{Introduction}

Framingham risk score (FRS), carotid intima-media thickness (IMT) and coronary artery calcium scoring (CAC) are indicators of atherosclerotic disease and predictors of cardiovascular events. However these techniques have technical and practical limitations; ultrasound-based carotid IMT is operator-dependent and assesses only vessel wall segments while coronary calcification is not reliably associated with atheroma burden in early disease. High-resolution carotid artery cardiovascular magnetic resonance (CMR) has intrinsic benefits that offer the potential to assesses the entire vessel wall, more accurately reflecting underlying changes.

\section{Purpose}

Our objectives were to assess the reproducibility of novel markers of carotid atherosclerosis using CMR and to determine their relationship with existing markers of cardiovascular risk.

\section{Methods}

A cohort of 147 asymptomatic individuals (110 male, age $53 \pm 11$ years) underwent comprehensive cardiovascular risk assessment including physician-estimated Framingham Risk Score (FRS), CAC scoring using a Siemens SOMATOM Sensation 16-slice multidetector computed tomography system, and CMR using a $1.5 \mathrm{~T}$ Siemens
Sonata system using a custom carotid coil. T1-weighted MR images of common and internal carotid arteries (CCA, ICA) were used to manually measure CCA IMT and semiautomatically measure novel carotid artery indices (Figure 1): vessel wall area (VWA), maximal wall thickness $(\mathrm{maxWT})$, and percentage atheroma volume $(\mathrm{PAV}=\mathrm{VWA}$ as a percentage of total vessel area). The relationship of our novel carotid artery parameters with existing markers of cardiovascular risk were assessed using Spearman's rank-order correlation coefficient and the Mann-Whitney U test (SPSS Inc, Chicago, IL). A random selection of patient images $(n=14)$ were retraced for inter- and intraobserver reproducibility (percentage coefficient of variation, \%CV).

\section{Results}

Mean FRS was $10.8 \pm 8.2 \%$. MRI indices (VWA, maxWT, PAV) were significantly associated with IMT $(\mathrm{r}=0.569, \mathrm{r}=$ $0.588, \mathrm{r}=0.575$; all $P<0.001$ ), but not with CAC. VWA and maxWT, but not PAV were associated with FRS $(\mathrm{r}=$ $0.254, P=0.004 ; \mathrm{r}=0.255, P=0.011$ ). Intra-observer and inter-observer \%CV for MRI indices were 2.9\% and 3.8\% respectively.

\section{Conclusion}

Our novel carotid indices are highly reproducible and significantly associated with established indicators of carotid 


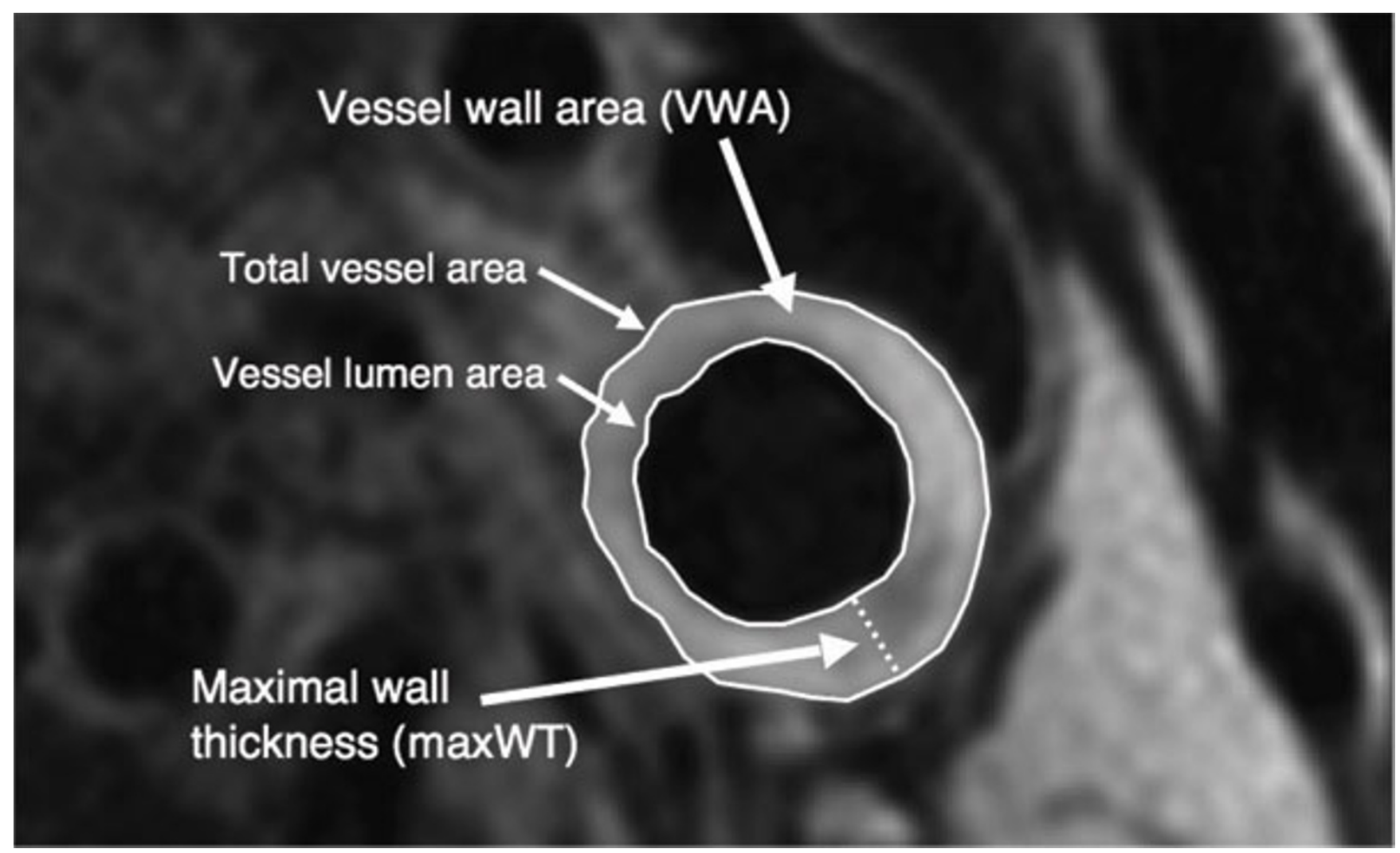

Figure I

Carotid artery measurements.

atheroma and cardiovascular risk (IMT and FRS). The lack of association with CAC may reflect a disproportionate relationship between the degree of calcification and atheroma in the carotid and coronary arteries. Follow-up of this cohort for cardiovascular outcomes data is likely to provide more direct information about risk, which will add to our understanding of atherosclerosis at different arterial sites and the role of CMR in predicting cardiovascular events.
Publish with Biomed Central and every scientist can read your work free of charge

"BioMed Central will be the most significant development for disseminating the results of biomedical research in our lifetime. "

Sir Paul Nurse, Cancer Research UK

Your research papers will be:

- available free of charge to the entire biomedical community

- peer reviewed and published immediately upon acceptance

- cited in PubMed and archived on PubMed Central

- yours - you keep the copyright
BioMedcentral 